\title{
Introduction to the special issue on data sources for interest group research
}

\author{
Beth L. Leech ${ }^{1}$ \\ Published online: 3 September 2020 \\ (c) Springer Nature Limited 2020
}

\begin{abstract}
Technological advances, increasing amounts of online governmental records, and transparency efforts by nonprofit organizations have led to a new abundance of data sources for studying the political activities of interest groups. In this special issue, fourteen sets of authors review these data sources and offer advice on how best to make use of them. The data sources discussed include reports filed as required by the Administrative Procedures Act, the Federal Election Commission, the Federal Communications Commission, the Foreign Agents Registration Act, and the Lobbying Disclosure Act, as well as data collected by the Center for Responsive Politics, the Comparative Agendas Project, the Comparative Interest Groups survey project, INTERARENA, INTEREURO, MapLight, the National Institute on Money in State Politics, the Political Group Communication Database, and the Wesleyan Media Project.
\end{abstract}

Keywords Interest groups · Organized interests · Lobbying · Political data sources

\section{Introduction}

Collecting data is time-consuming, difficult work. Researchers are (usually) rational actors, and so there is a tendency for scholarship to focus on questions that can be easily answered using existing data. If the government or another large institution collects relevant information and makes it publicly available, then researchers save the time of collecting the data themselves and are able to publish more work. Thus, we see that most economics research is based on government indicators, most congressional research focuses on roll call votes (rather than the complex and mostly undocumented process of bill creation), and most public opinion scholars focus on existing surveys and existing survey questions. It also is why, in the 1980s, the US interest group literature was dominated by studies considering whether Political

Beth L. Leech

Leech@polisci.rutgers.edu

1 Rutgers University, 89 George St., New Brunswick, NJ 08904, USA 
Action Committee (PAC) contributions (which the Federal Election Commission started tracking in 1976) affected how members of Congress voted. PAC data were some of the easiest data for interest group scholars to access.

The data that are easiest to access do not always speak to the most interesting research questions, however. One of the many critiques of the interest group literature made more than 2 decades ago in the book Basic Interests (Baumgartner and Leech 1998) was that scholars had spent too little time analyzing the policyrelated activities of interest groups (compared to the time spent on questions of why individuals join groups). And, the book argued, when scholars did consider policyrelated activities, most of their studies focused on PAC contributions and were narrow empirically, often focusing on a single interest group or a single congressional vote.

These critiques are no longer true today, as this special issue of Interest Groups \& Advocacy clearly shows. There is a growing range of data sources available for the study of the advocacy efforts of organized interests and a growing ability to address interesting questions that had long been left on the sidelines. Some of the new data sources are available thanks to advances in computing power and machine learning techniques. Others are the result of years of painstaking work by researchers who refused to take the easy way out, many of them joining together in groups to make larger-scale projects possible. But one of the strongest commonalities of these new data is that they have often been helped into being by government rules or the efforts of nonpartisan, nonprofit organizations.

\section{Governmental requirements as generators of data}

Governmental efforts provide the initial data collection for many of the datasets described in this special issue: The reports and other documents filed throughout the year in the USA as the result of the Lobbying Disclosure Act, the Foreign Agents Registration Act, the Federal Election Campaign Acts, and the Administrative Procedures Act provide the most prominent examples. Likewise, in the European Union and many of its constituent countries, parliamentary and ministerial rules have led to the systematic collection of written statements on proposed policies submitted by interest groups. These data sources, however, were not created with political scientists' analysis needs in mind, and sometimes, a great deal of work is needed before they become useful to researchers. The authors of the articles in this issue are performing a much-needed service by their cleaning of these data and their instructions about how to make best use of these data.

This special issue begins with a piece by Timothy LaPira and Herschel Thomas III that celebrates 25 years of the US Lobbying Disclosure Act (LDA) of 1995 (LaPiraand Thomas 2020). When the first lobbying disclosure reports were collected by the government in 1996, they provided the most detailed look to date of the national-level lobbying population in the USA. The reports provided information about the total number of lobbying organizations, the number of lobbyists, the amount spent on lobbying, and the breadth of issues lobbied on-information that before was available only rarely and only piecemeal, through surveys or interviews 
of a sample of organizations. Although the LDA made this information more easily accessible, it still was not an easy task to compile that information, as LaPira and Thomas document. As these data have moved from microfiche to online databases, the task has become somewhat easier, but the data are still sometimes tricky to deal with. LaPira and Thomas provide tips to make that process easier for researchers new to the LDA data.

Likewise, the US Foreign Agents Registration Act (FARA) has long required foreign countries and companies that lobby to file semiannual reports. These reports now are archived, in imaged form, on the US Department of Justice website. In her article in this issue, Hye Young You describes how she extracted data from these images to create a dataset comprising all filings from 1942 to 2017, for a total of 46,107 reports about 201 countries (You 2020). Her work makes that data much more easily accessible than it would be for any researcher starting with just the FARA website. In the article, You also provides guidance for researchers who might want to repeat what she did, extending the dataset beyond 2017.

Federal Election Commission (FEC) data might once have been over-used by researchers, but information about campaign contributions remains an important resource, especially as decisions by the US Supreme Court have broadened the ability of interest groups to involve themselves in elections. Christine Williams, Jeff Gulati, and Mateusz Zeglen use their article in this issue to provide an overview of FEC rules for researchers new to the complex structure of the data (Williams et al. 2020). They also point readers to a series of nonpartisan nonprofits that provide easier access to these data, sometimes with additional information coded and added in. Finally, they provide a step-by-step guide to how to extract and manipulate FEC data to investigate a specific research question. This is case in point about how often good data require multiple creators: a large institution (in this case, a government agency) to collect the data, nonprofits to help create easier access to the data, and the hard work of researchers to find quicker and better ways to turn the data into a usable dataset.

Taking the case of Germany, Daniel Rasch, Florian Spohr, Rainer Eising, and Simon Ress provide a guide to using written interest group statements submitted to parliamentary committees and the corresponding ministries to identify participants in the advocacy process and identify their respective policy preferences (Rasch et al. 2020). Although these data can be downloaded directly from governmental websites, the work then is far from over. Rasch and his colleagues provide a thorough discussion of the advantages and shortcomings of these data and discuss methods of coding the written statements.

\section{Nonprofit organizations as sources of data}

Nonprofit charitable organizations are also an important source of the data described in several of the articles in this issue. The raw data described by Geoffrey Lorenz, Alexander Furnas, and Jesse Crosson, for example, come from MapLight, a nonpartisan, 501(c)(3) charitable organization that collects (and freely shares) data related to the role of money in politics. Lorenz, Furnas, and Crosson describe the 
structure of these data-more than 130,000 observations of organizations taking positions for and against legislation in Congress between the 109th and 115th Congresses (2005-2018) — and give examples of how these data have been, and might be, used (Lorenz et al. 2020).

Several of the articles in this issue, including Williams, Gulati, and Zeglen (2020), make use of data from the nonprofit, nonpartisan Center for Responsive Politics (CRP) and its Open Secrets website. CRP's data on campaign finance (which in turn it collected largely from the FEC) and lobbying (which CRP collects from the government LDA reports) are widely used by researchers because they are cleaner, better organized, and generally easier to use than the raw data collected by the government. Here, we see data collection efforts by the government, a nonprofit, and dedicated scholars coming together to make interest group activities more transparent.

And finally, the nonprofit National Institute on Money in State Politics uses its FollowTheMoney.org website to share data about campaign finance and lobbying. It, in turn, collects those data from the 50 individual US states-which have laws requiring lobbyists and interest groups to register with the state an-and compiles those data for researchers, the public, and the media.

\section{Data collection through research grants}

Of course, government and foundation grants to researchers have also been important to the creation of large, shared data sets that may be used for studying interest groups. The Policy Agendas data that form the starting point for the Comparative Agendas Project (CAP), for example, were first created with the help of two large grants from the National Science Foundation (and subsequent funds from smaller grants and support from several different universities). In this special issue, E.J. Fagan and Brooke Shannon (Fagan and Shannon 2020) describe how to leverage these data-which are organized at the level of the policy topic-to connect to interest group activity. This is an example of a data source that helps make first steps easy, although there is still the difficult job of making the interest group connection. Information on the number of US associations linked to each policy area can be done using the Comparative Agendas dataset drawn from the Encyclopedia of Associations. But links to other sources of information about interest group behavior-congressional testimony, LDA reports, or interviews and surveys done by the researcher-still require extensive effort beyond the existing datasets. Still, Fagan and Shannon make a convincing case that this is worth doing, both because of the extensive nature of the policy datasets themselves and because use of the CAP coding scheme allows new datasets to connect to so many other datasets.

Governmental grants in the European Union have been generous to interest group research in recent years (at least compared to US funding sources), as evidenced by the INTEREURO, INTERARENA, and the Comparative Interest Group survey (CIG) projects discussed in this issue. Large projects like these show the impact that coming together as researchers can have, and also how such joining together becomes easier when there is funding to be had. The INTEREURO project, which 
already has been well documented in an earlier special issue of this journal (Lowery 2014), focused primarily on lobbying at the level of the European Union. Growing out of that project is the Comparative Interest Group (CIG) survey project, described in this issue by Jan Beyers, Danika Fink-Hafner, William Maloney, Meta Novak, and Frederik Heylen (Beyers et al. 2020). The project compiles large-scale survey data from interest groups in eight countries and at the EU level, offering a wealth of data for future researchers, as well as a baseline against which to compare future surveys.

Another ambitious, multi-country effort, the INTERARENA project, is described in this issue by Anne Binderkrantz, Peter Munk Christiansen, and Helene Helboe Pedersen (Binderkrantz et al. 2020). The authors were part of a group of researchers who mapped interest group access to the administration, parliaments, and the news media in the Netherlands, Denmark, and the UK. The project was striking because of its broad definition of access-considering interest groups' abilities to be heard not only in formal governmental settings, but also in the news media. Access by these groups thus can be compared across venues, as well as by country, policy area, and group type. The data are now publicly available, and the authors give guidance on what the datasets include.

Foundations and universities also serve as sources of funding for large collaborative projects. Michael Franz, Erika Fowler, and Travis Ridout, in their article in this issue (Franz et al. 2020), describe three sources of information about interest group-sponsored political ads. One of these, the Wesleyan Media Project (together with its predecessor, the Wisconsin Advertising Project) has been tracking televised political ads in every federal election since 1998. This project has received funding over the years from the Democracy Fund, the Knight Foundation, the MacArthur Foundation, the Rockefeller Brothers Fund, the Sunlight Foundation, and four universities. Other sources of data about political ads discussed in the article include a governmental source - the US Federal Communications Commission (FCC), and the authors give guidance about the additional coding that is necessary to make the data useable by researchers. Finally, the authors give detailed guidance about making use of social media platforms' records of political advertising, focusing on data provided by Facebook.

\section{New technology and data creation}

Government provides data, nonprofits ease access to data, and grants help scholars make sense of it all. But throughout these data production activities runs a stream of technological improvements. Sometimes, it is as simple as subscribing to an e-mail list, as Zachary Albert (Albert 2020) describes in his article in this issue. Twenty years ago, it was not a safe assumption that most group supporters would have their own e-mail addresses, and many interest groups did not have their own websites or use e-mail extensively. Today, by comparison, e-mails from advocacy groups are "frequent, abundant, and simple to collect," as Albert writes. The article also introduces readers to the Political Group Communication Database, which brings together a continually updated dataset of e-mails from a wide range of interest groups and think tanks. 
A more complex technological solution comes from Alex Garlick and John Cluverius in their article "Automated Estimates of State Interest Group Populations" (Garlickand Cluverius 2020). Using data collected by the National Institute on Money in State Politics (mentioned above), they sort the listed organizations-more than 600,000 of them, responsible for more than two million state lobbying registrations over an eleven-year period-by economic sector using automated coding techniques. This allows for investigations into the political strength and impact of these various economic sectors as well as the testing of hypotheses about the causes of organizational growth. These data had previously been coded by hand by Holyoke (2019) in a years-long process. Garlick and Cluverius' article uses the Holyoke data and other sources to validate the automated process, opening the doors to the ability to relatively quickly estimate these populations in future years.

The ability of government to post data online means that it is no longer necessary to visit a government office to collect data from paper records. That advance, combined with efforts by some agencies to provide more transparency, has made it possible to consider previously unstudied federal agencies. In their article about data from the President's Office of Information and Regulatory Affairs (OIRA), Simon Haeder and Susan Yackee in this issue describe the benefits and shortcomings of OIRA's online logs of meetings, and how these have improved since an executive order by President Clinton in 1993 first started the practice (Haeder and Yackee 2020). Their work will make it possible for others to make use of these data as well.

Similarly, data on who comments in rulemaking procedures have become more accessible over time, but variations in whether or not the data are machine-readable make compiling those data less than straightforward. In their article "Data and Methods of Analyzing Special Interest Influence in Rulemaking," Daniel Carpenter, Devin Judge-Lord, Brian Libgober, and Steven Rashin (Carpenter et al. 2020) provide detailed technical instructions about how best to access the information in Regulations.gov, the Federal Register, the Unified Agenda, and individual agency websites - and provide suggestions for how researchers might build data resources for the future.

\section{Conclusion}

Our special issue concludes with a review essay by Abigail Vegter, Jami Taylor, and Donald Haider-Markel, who compile a list of other existing data sources at the US national and state levels that could be of use to future researchers (Vegter et al. 2020). Along the way, the authors provide a history of empirical interest group projects. Some of these are projects done by single scholars-the surveys done by Jack Walker (1991) in the 1980s, for example-but the pattern of large-scale empirical work coming primarily from groups of scholars working together exists in this past work as well. The work of Heinz et al. (1993), for example, involved four senior scholars and produced one of the largest troves of interest group data in existence, data which still are serving as a source against which to test new hypotheses.

Political scientist Douglas Arnold once called the interest group subfield "theory rich and data poor," noting that scholars who studied interest groups, unlike those 
who studied electoral behavior, had not benefited from large-scale, institutionally financed data collection (Arnold 1982). By comparison with electoral studies, that statement may well still be true, but in absolute terms the data available to interest group scholars have grown exponentially in the 4 decades since Arnold wrote those words, and the pace of data acquisition has been especially fast during the most recent decade.

Basic Interests called upon scholars to broaden the empirical scope of interest group studies by overcoming their own collective action dilemma. It noted that although work on narrower topics with a single author allowed credit to be more easily assigned, it was only by coming together as groups of researchers that largerscale projects would be possible. As interest group scholars, we know that the collective action dilemma can be hard to overcome, but we also know which circumstances make coming together easier. Almost 30 years ago, Walker (1991) described one of the central ways that such organizing can succeed: with the help of "patrons" and other large donors. The data described by the authors in this issue have become available in large part because of subsides from government, universities, and nonprofits. Just as Walker showed that most non-occupational interest groups relied on large donors at their founding, so have the new data sources described in this issue relied heavily on resources from existing institutions. The researcher as entrepreneur (Salisbury 1969) is a necessary and important first step, but without resources, even the most determined entrepreneur may founder. This special issue illustrates how the actions of governments, nonprofits, and funders, combined with the hard work of the researcher-entrepreneur, can make it possible to get the data needed to answer important questions about the role of interest groups in the policy arena.

\section{Compliance with ethical standards}

Conflict of interest The corresponding author states that there is no conflict of interest.

\section{References}

Albert, Zachary. 2020. Click to Subscribe: Interest Group Emails as a Source of Data. Interest Groups \& Advocacy. https://doi.org/10.1057/s41309-020-00097-7.

Arnold, R.Douglas. 1982. Overtilled and Undertilled Fields in American Politics. Political Science Quarterly 97: 91-103.

Baumgartner, Frank R., and Beth L. Leech. 1998. Basic Interests: The Importance of Groups in Politics and in Political Science. Princeton, NJ: Princeton University Press.

Beyers, Jan, Danica Fink-Hafner, William A. Maloney, Meta Novak, and Frederik Heylen. 2020. The Comparative Interest Group-Survey Project: Design, Practical Lessons, and Data Sets. Interest Groups \& Advocacy. https://doi.org/10.1057/s41309-020-00082-0.

Binderkrantz, Anne S., Peter M. Christiansen, and Helene H. Pedersen. 2020. Mapping Interest Group Access to Politics: A Presentation of the INTERARENA Research Project. Interest Groups \& Advocacy. https://doi.org/10.1057/s41309-020-00095-9.

Carpenter, Daniel, Devin Judge-Lord, Brian Libgober, and Steven Rashin. 2020. Data and Methods for Analyzing Special Interest Influence in Rulemaking. Interest Groups \& Advocacy. https://doi. org/10.1057/s41309-020-00094-w. 
Fagan, E.J., and Brooke Shannon. 2020. Using the Comparative Agendas Project to Examine Interest Group Behavior. Interest Groups \& Advocacy. https://doi.org/10.1057/s41309-020-00081-1.

Franz, Michael M., Erika Franklin Fowler, and Travis N. Ridout. 2020. Accessing Information About Interest Group Advertising Content. Interest Groups \& Advocacy. https://doi.org/10.1057/s4130 9-020-00083-z.

Garlick, Alex, and John Cluverius. 2020. Automated Estimates of State Interest Group Lobbying Populations. Interest Groups \& Advocacy. https://doi.org/10.1057/s41309-020-00091-z.

Haeder, Simon F., and Susan Webb Yackee. 2020. Out of the Public's Eye? Lobbying the President's Office of Information and Regulatory Affairs. Interest Groups \& Advocacy. https://doi.org/10.1057/ s41309-020-00093-X.

Heinz, John P., Edward O. Laumann, Robert L. Nelson, and Robert H. Salisbury. 1993. The Hollow Core: Private Interests in National Policymaking. Cambridge, MA: Harvard University Press.

Holyoke, Thomas T. 2019. Dynamic State Interest Group Systems: A New Look with New Data. Interest Groups \& Advocacy 8: 499-518. https://doi.org/10.1057/s41309-019-00058-9.

LaPira, Timothy M., and Herschel F. Thomas. 2020. The Lobbying Disclosure Act at 25: Challenges and Opportunities for Analysis. https://doi.org/10.1057/s41309-020-00101-0.

Lorenz, Geoffrey M., Alexander C. Furnas, and Jesse M. Crosson. 2020. Large-N Bill Positions Data from MapLight.org: What Can We Learn from Interest Groups' Publicly Observable Legislative Positions? Interest Groups \& Advocacy. https://doi.org/10.1057/s41309-020-00085-x.

Lowery, David. 2014. Introduction to the Special Issue of IG\&A on Methodological Issues of Large$\mathrm{N}$ Research on Interest Representation. Interest Groups \& Advocacy 3: 123-125. https://doi. org/10.1057/iga.2014.7.

Rasch, Daniel, Florian Spohr, Rainer Eising, and Simon Ress. 2020. Uncovering Interest Group Participation in Germany: Web Collection of Written Statements in Ministries and the Parliament. Interest Groups \& Advocacy. https://doi.org/10.1057/s41309-020-00099-5.

Salisbury, Robert H. 1969. An Exchange Theory of Interest Groups. Midwest Journal of Political Science 13 (1): 1-32. https://doi.org/10.2307/2110212.

Vegter, Abigail, Jami K. Taylor, and Donald P. Haider-Markel. 2020. Old and New Data Sources and Methods for Interest Group Research. Interest Groups \& Advocacy. https://doi.org/10.1057/s4130 9-020-00102-z.

Walker, Jack L. 1991. Mobilizing Interest Groups in America: Patrons, Professions, and Social Movements. Ann Arbor: University of Michigan Press.

Williams, Christine B., Jeff Gulati, and Mateusz Zeglen. 2020. Following the Money: Uses and Limitations of FEC Campaign Finance Data. Interest Groups \& Advocacy. https://doi.org/10.1057/s4130 9-020-00096-8.

You, Hye Young. 2020. Foreign Agents Registration Act: A User's Guide. Interest Groups \& Advocacy. https://doi.org/10.1057/s41309-020-00100-1.

Publisher's Note Springer Nature remains neutral with regard to jurisdictional claims in published maps and institutional affiliations. 